\title{
The Circadian System in Alzheimer's Disease: Disturbances, Mechanisms, and Opportunities
}

\author{
Andrew N. Coogan, Barbora Schutová, Susanne Husung, Karolina Furczyk, Bernhard T. Baune, \\ Peter Kropp, Frank Häßler, and Johannes Thome
}

\begin{abstract}
Alzheimer's disease (AD) is a devastating neurodegenerative condition associated with severe cognitive and behavioral impairments. Circadian rhythms are recurring cycles that display periods of approximately 24 hours and are driven by an endogenous circadian timekeeping system centered on the suprachiasmatic nucleus of the hypothalamus. We review the compelling evidence that circadian rhythms are significantly disturbed in $A D$ and that such disturbance is of significant clinical importance in terms of behavioral symptoms. We also detail findings from neuropathological studies of brain areas associated with the circadian system in postmortem studies, the use of animal models of $A D$ in the investigation of circadian processes, and the evidence that chronotherapeutic approaches aimed at bolstering weakened circadian rhythms in AD produce beneficial outcomes. We argue that further investigation in such areas is warranted and highlight areas for future research that might prove fruitful in ultimately providing new treatment options for this most serious and intractable of conditions.
\end{abstract}

Key Words: Alzheimer's disease, chronotherapy, circadian, dementia, SCN, sleep

$\mathrm{D}$ isturbances of daily behavioral and sleep patterns are commonly described in neurological and psychiatric disorders (1). In Alzheimer's disease (AD) such behavioral disturbance is a leading reason for institutional care in moderate to severe AD (2). There is considerable evidence that disturbances of sleep-wake cycles are related to alterations in the suprachiasmatic nucleus (SCN), the master circadian pacemaker (3). The SCN is a small nucleus of the anterior hypothalamus located directly dorsal to the optic chiasm (from which it receives direct retinal innervations) that is composed of a neurochemically and functionally heterogenous assembly of neurons (4). Circadian rhythms are generated as an output of the clock gene cycle, produced by a series of interlocking transcriptional feedback/feedforward loops of a panel of clock genes (e.g., PER1,2, CRY1,2, CLOCK, $B M A L 1)$. Such cycles drive the rhythmic expression of clockcontrolled genes, and ultimately such molecular cycles are translated into physiological and behavioral circadian rhythms $(3,5)$. Outside of the SCN there are circadian oscillators throughout the brain and periphery, and the circadian network normally functions as a complex and distributed system that imposes temporal architecture on physiology and behavior (5). There are also circadian rhythms in neurocognitive parameters $(6,7)$ and disruption of circadian rhythms leads to cognitive impairments (8). Circadian dysfunction also impacts negatively on immune, metabolic, and cardiovascular systems $(9,10)$. Such circadian alterations are increasingly being explored with regard to both

From the Department of Psychology (ANC), National University of Ireland, Maynooth, Republic of Ireland; Clinic and Policlinic for Psychiatry and Psychotherapy (BS, SH, KF, JT); Institute of Medical Psychology and Medical Sociology (PK); Clinic for Child and Adolescent Psychiatry, Neurology, Psychosomatics and Psychotherapy, University of Rostock, Rostock, Germany; Department of Psychiatry (FH, BTB), University of Adelaide, Adelaide, Australia; and the College of Medicine (JT), Swansea University, Swansea, Wales, United Kingdom.

Address correspondence to Johannes Thome, Ph.D., M.D., Department of Psychiatry, University of Rostock, Gehlsheimer Straße 20, 18147

Rostock, Germany; E-mail: johannes.thome@med.uni-rostock.de. Received Aug 30, 2012; revised and accepted Nov 20, 2012. functional decline during healthy aging and in age-related diseases (11). In this review we examine the evidence with regard to circadian alterations in $A D$ and explore the therapeutic avenues that arise and the opportunities for advancement at the interface between dementia research and chronobiology.

\section{Functional Studies of Circadian Disruption in AD}

Many studies to date have examined the relationship between aging and circadian function, with decreased amplitude but not period of the rhythm as well as alterations in circadian phase being commonly reported findings (12) (see the glossary of chronobiological terminology in Supplement 1). These alterations in circadian parameters are exacerbated in $A D$, the most apparent deficit being fragmentation of the sleep-wake cycle leading to increased nocturnal awakenings and increased daytime sleep bouts (13). The use of noninvasive actigraphy (usually via a wristworn accelerometer) has been beneficial in monitoring rest/ activity cycles in dementia patients since the early 1990s $(14,15)$. Later rest/activity cycles of home-dwelling $A D$ patients were examined over one year, and those with mild dementia displayed rhythms not significantly different from those of control subjects, whereas those with moderate dementia displayed fragmentation of the rhythm and decreased amplitude, although these effects were not correlated with the severity of the dementia (16). Van Someren et al. (17) reported that rhythms were most fragmented in institutionalized $A D$ patients and that higher levels of daytime activity predicted more coherent rhythms, whereas lower levels of daytime activity predicted rhythm fragmentation. Changes in circadian parameters are not equivalent across different types of dementias; there are differences in the nature and magnitude of rhythm disturbance in AD, frontotemporal dementia, and diffuse Lewy body disease (18). The overall locomotor changes that occur in $A D$ seem to be related to more specific behavioral changes, for example in meal time, which in turn might be linked to poorer nutritional outcomes (19). Further evidence for the importance of circadian rhythms in $A D$ is provided by the finding that higher daytime activity levels and lower nocturnal activity (i.e., consolidated, nonfragmented sleep/wake cycle organization), is strongly associated with increased wellbeing and functional status (20). Results from a large prospective study indicate that changes in circadian activity patterns (decreased 
rhythm amplitude, phase-delays) are significant predictors of subsequent $A D$ or mild cognitive impairment, suggesting that compromised rhythms might be a preclinical phenomenon (21). Another point of interest is that anti-psychotic medication used in the clinical management of AD might impact on circadian rhythms (22), because these medications might impact on the molecular components of the circadian system (23).

General activity is not the only parameter that can be used to assess circadian rhythmicity at the gross level in AD. Skin temperature monitoring demonstrates that proximal but not distal skin temperature is raised in the daytime in AD patients compared with elderly control subjects, with no nocturnal difference in either distal or proximal skin temperature (24). Proximal skin temperature was also positively correlated with daytime sleepiness in both AD patients and healthy control subjects. One explanation for these findings is that alterations in proximal skin temperature in $A D$ are functions of altered circadian clock control of autonomic processes involved in the regulation of skin temperature.

A potential consequence of disrupted circadian rhythms in AD is the manifestation of rhythms in behavioral agitation. Patients affected by $A D$ often develop varying disruptive behavioral symptoms, such as agitation and restlessness, verbal outbursts, wandering, physical threats, and aggression (25). "Sundowning" is the term given to the occurrence of the aforementioned symptoms during the late afternoon or early evening $(26,27)$. The prevalence of sundowning in $A D$ is reported as being between $13 \%$ and $66 \%(28-30)$. The temporal nature of sundowning is suggestive of a circadian origin: nonlinear analyses of actigraphic data in $A D$ show that higher levels of motor regularity, especially during the night, are associated with aggressive behavior in AD patients (31).

Insight into the nature of the circadian disturbances that occur in $A D$ is provided through the analysis of actigraphic activity data for scale invariance of activity fluctuations, which was reduced in AD patients and most reduced in the oldest, most severely demented patients (32). This is of interest, because scale invariance in activity patterns is found in rodents to be dependent on the SCN (33), and so the changes observed in AD might be taken as indicative of changes occurring in the master clock that are then translated into gross patterns of behavior. This finding is in accordance with the findings from neuropathological studies discussed later.

There are some significant issues that limit the interpretation of functional studies of circadian rhythms in AD. First is the nature of the diagnosis commonly used to select study populations, that of dementia of the probable Alzheimer's type, which cannot be confirmed until postmortem examination (itself not routinely carried out). Given that dementia is a symptom of many other diseases of old age and that postmortem examination might not confirm a diagnosis of $A D$ (e.g., $15 \%$ of diagnoses are not confirmed at autopsy [34]), it seems likely that the populations examined in the aforementioned studies represent a heterogeneous population representing both $A D$ and non-AD dementias. Another caveat for actigraphy-based studies is the ease with which rhythms might be masked by environmental factors, such as nursing care, occupational therapies, and a host of societal factors for studies in AD patients in the home setting. Such concerns are not just limited to dementia studies and do not negate the usefulness of actigraphy to gain significant insight into circadian rhythm disturbance in $A D$, but they do highlight that care needs to be taken in the interpretation of results from such studies. Supplement 1 contains information on neuroendocrine changes in AD.

\section{Postmortem and Neuropathology Studies}

Postmortem studies have assessed neuropathological changes within the SCN in both healthy aging and in dementia and neurodegenerative disease (12). Stopa et al. (35) evaluated the degenerative changes in the SCN from patients with severe AD and found neuronal loss and tangles, indicating that the SCN is affected by $A D$, whereas amyloid plaques were only seldom noted in the SCN. Overall SCN volume has been reported to decrease in dementia of the Alzheimer's type (36), and the expression of the neuropeptide vasoactive intestinal polypeptide (VIP) was found to be decreased in the presenile male SCN (37). There is also a loss of rhythmicity of SCN arginine vasopressin (AVP) during aging (38), and in AD this loss of AVP neurons and rhythmicity is accelerated $(39,40)$. Loss of neurotensin-expressing neurons in the SCN of AD patients is also reported along with increased astrocytes (35). Because VIP, AVP, and neurotensin are known to alter SCN neuronal function $(41,42)$, their loss during AD might be of particular functional consequence. Interestingly, there is evidence to suggest that neuropeptide alterations in the SCN occur at early stages of $A D$ and might preface cognitive decline (43). Harper et al. (44) also provide evidence that neuropathological progression (as measured by Braak stage) in postmortem AD brains is associated with the severity of circadian abnormalities, suggesting that the circadian rhythm disturbances in $A D$ are directly linked to the central neuropathology of the disease. There is also evidence for neurodegeneration in the SCN in both $A D$ and frontotemporal dementia, as determined by the neuron/glia ratio, and this degeneration correlates to the magnitude of circadian rhythm impairment in core body temperature and activity parameters (45). Loss of SCN neurotensin cells was also associated with dampened activity rhythm amplitude but not with increased fragmentation of the rhythm, although loss of AVP neurons in the dorsomedial SCN was associated with rhythm fragmentation but not dampened amplitude (45). Expression of the MT1 melatonin receptor in the SCN is also markedly decreased in late stage AD (40). Supplement 1 contains an overview of circadian influences on $A \beta$ levels.

Another area that undergoes neurodegeneration in $A D$ and might be important for circadian rhythm disturbance is the cholinergic basal forebrain. Cells of the nucleus basalis project to the SCN (46), there is cholinergic innervations of the SCN (47), and cholinergic agents act in the SCN to modulate circadian rhythms (48). The question should then be posed as to what effect the loss of cholinergic cells in the basal forebrain in $A D$ might have on circadian function. Lesion of the cholinergic projection to the SCN in rats leads to alterations in the phaseshifting effects of light on circadian rhythms (49), although another study in using lesions of the cholinergic medial septum did not find alterations in circadian parameters (50). Differences between these studies might be due to the neuroanatomical locations of the lesion as well as differences in the behavioral paradigms examined. The study of Wisor et al. (51) reports that alterations in non-rapid eye movement sleep in the Tg2576 mouse model of AD might be due to alterations in cholinergic transmission. On balance, it seems reasonable to suggest that further studies examining the role of cholinergic depletion in circadian disturbance in AD (e.g., postmortem analysis of acetylcholine fibers in the SCN) are needed (Figure 1). 
Behavioral Disturbance, Cognitive Decline

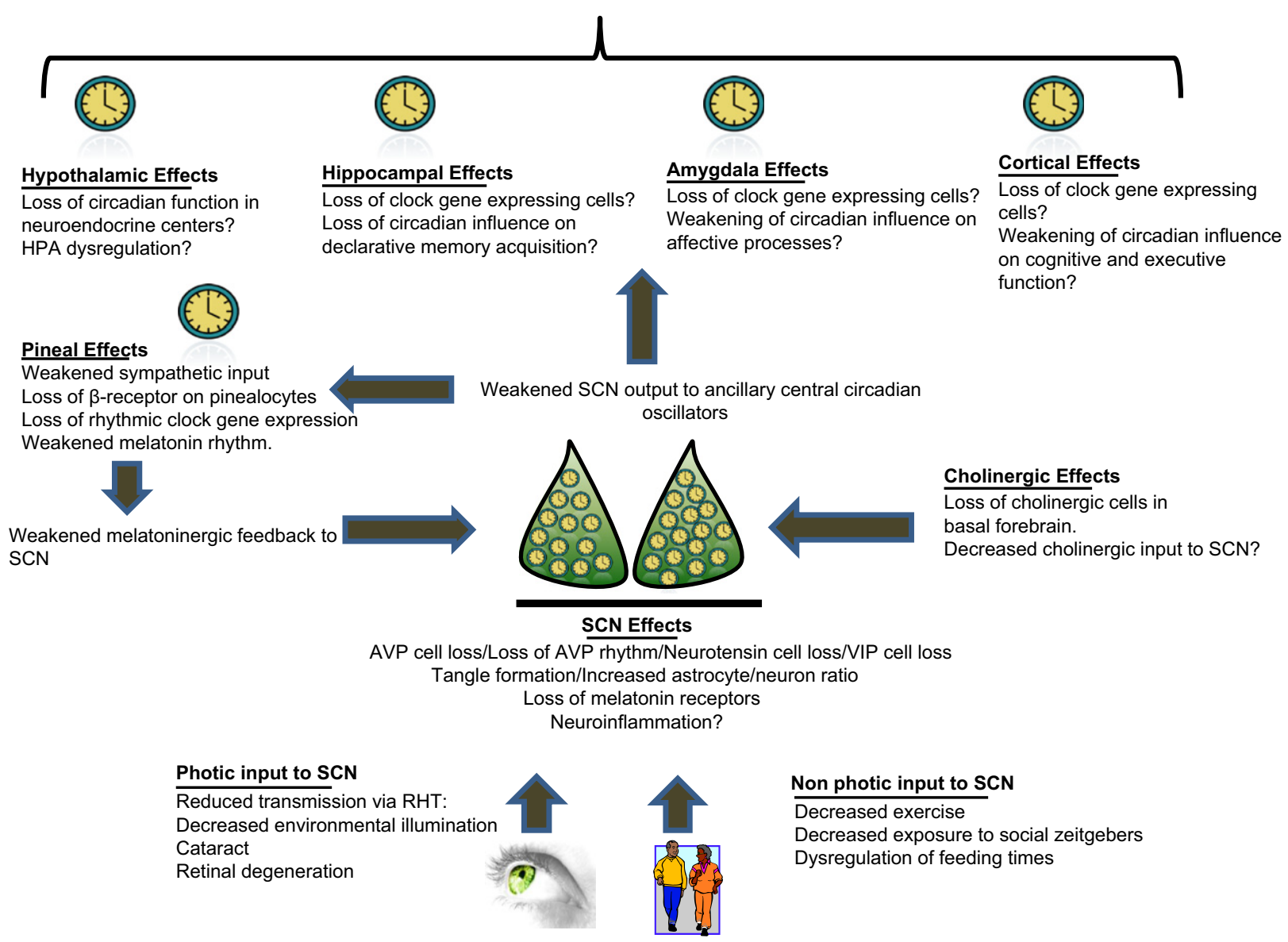

Figure 1. Graphic illustrating potential pathways by which circadian rhythms might be disturbed in Alzheimer's disease and how such disturbances might impact on physiological, cognitive, and behavioral changes in Alzheimer's disease. AVP, arginine vasopressin; HPA, hypothalamic-pituitary-adrenal; RHT, retinohypothalamic tract; SCN, suprachiasmatic nucleus; VIP, vasoactive intestinal polypeptide.

\section{Clock Gene Cycles in AD}

Given the key roles played by clock genes in the generation of physiological and behavioral circadian rhythms, it is of particular interest to inquire how clock gene expression cycles are affected in $A D$ and other dementias. Such work is difficult, due to the dependence on postmortem tissue to examine clock gene expression in the SCN and other central sites. Recently, the expression of the clock genes PER1, PER2, and BMAL1 was examined in the bed nucleus of the stria terminalis (BNST), the cingulate cortex, and the pineal gland (52). These are core clock genes that serve to regulate the near-24 -hour regulation of clock-controlled gene transcription and ultimately manifest circadian rhythmicity at the physiological level. Both the BNST and the cingulate cortex have previously been shown to express rhythmic clock genes $(10,53)$. Similar peak times for PER1 and PER2 in control subjects in the active phase were reported, whereas BMAL1 was shown to peak in the night (52). Interestingly, PERs and BMAL1 displayed significant 24-hour rhythmicity in the brains of AD patients. However, a state of desynchrony in oscillation between cortex, pineal gland, and the BNST in AD patients was found, possibly caused by the degeneration of the SCN cells in AD brains (52). Given the roles of the BNST and cingulate cortex in decision-making and motivated behaviors and the position of the pineal gland as a major output of the SCN, abnormal rhythms in these brain regions or lack of coordination between them might contribute to cognitive and sleep-wake deficits in AD patients. Rhythmic expression of BMAL1, CRY1, PER1 in human pineal has been reported, and these rhythms are lost in pineals from both preclinical and clinical AD patients (40). Tseng et al. (54) examined expression of PER1 in peripheral leukocytes during different sleep stages in healthy control subjects, those with mild cognitive impairment, and patients with $A D$ and reported no difference across the groups in terms of PER1 expression. Although such observations are valuable, their interpretation is hampered by the lack of data on clock gene expression in SCN tissue. There seems to be an opportunity here to use recently developed methods of assaying molecular rhythms in peripheral tissues $(55,56)$ in $A D$ to gain a more systematic insight into circadian rhythm dysfunction than is likely to be afforded by postmortem studies (Supplement 1 contains an overview of clock gene polymorphisms in $A D$ ).

\section{Findings from Animal Models of AD}

Given the difficulty in assessing core circadian processes in demented patients (e.g., the unsuitability of forced desynchrony or constant condition protocols needed to assess parameters such as circadian period), attention has been paid to using animal 
models of $A D$ to assess circadian alterations. There is no one animal model of $A D$ that recapitulates fully $A D(57)$, and many animal models of AD model the amyloid but not the $\tau$ pathology associated with AD. However, such models can provide valuable insight and allow for full behavioral and molecular characterizations from a circadian standpoint. There is the added complexity of the age $\times$ background interactions in transgenic animals, and not all studies examining circadian rhythms in animal models of AD have adopted longitudinal approaches sufficient to address this important concern. Furthermore, many studies to date do not undertake a comprehensive circadian analysis, and so only part of the picture is available for many of these AD models.

In rats, injection into the SCN of transgenic cells overexpressing $\beta / A 4$ leads to significant deterioration of the circadian rhythm, in terms of both fragmentation and rhythm period and power (58). In hamsters, injection of $\beta$ amyloid 25-35 into the SCN resulted in phase-advanced and less consistent diurnal rhythms, effects that were attenuated by melatonin (59). In the amyloid precursor protein (APP) 23 mouse model activity levels centered around "dusk" were diminished, although overall activity levels in the active dark phase were increased (60). In a further study on APP23 mice, activity in the second half of the active phase is increased (61), and this might be analogous to sundowning in AD patients, which also occurs in the second half of the active phase. In the APP mouse there are alterations in the temporal organization of anxiety-like symptoms that emerge when compared with age-matched control subjects (62) and again suggest that such changes might be important for understanding circadian influences on sundowning.

The Tg2576 mouse model shows marked lengthening of the free-running period in constant darkness, although under a light/ dark cycle activity was confined mostly to the dark period, indicating that-although there might be alterations to the period - these are compensated by normal entrainment mechanisms under a light/dark cycle (51). In a further study of the Tg2576 model, no changes across the lifecourse in period, activity onsets, or offsets were reported, although there were ultradian changes in activity parameters (63). This finding might be consistent with the finding that there was no evidence of amyloid deposits in or nearby the SCN in the Tg2576 mice. In the TgCRND8 model diurnal organization of behavior was altered, with more daytime activity and lessened levels of nocturnal activity, suggesting rhythm fragmentation, and these effects are noted before the appearance of A- $\beta$ neuropathology (64). Modifications of diurnal patterns of activity in APP knockout animals can be rescued by the secreted $\beta$-amyloid precursor protein ectodomain APPs $\alpha$ (65).

The 3xTg mouse model, which displays both A- $\beta$ and $\tau$ pathology, did not display abnormalities in free-running period or photic phase-shifting but did display markedly reduced activity levels after the onset of A- $\beta$ pathology (66). These mice also displayed changes in the neuropeptidergic content of the SCN (AVP- and VIP-expressing neurons), a situation that echoes findings from postmortem studies of the SCN in AD. Another recent study on the $3 x \mathrm{Tg}$ model shows exaggerated amplitude and a phase advance of the core body temperature rhythm, and these effects were not dependent on cyclooxygenase and occurred in the absence of neuropathology in the hypothalamus (67). Analysis of the A $\beta$ PPswe/PSEN1 A246E mouse-which carries transgenes for both APP and presenilin-1—shows that, although activity levels are increased, circadian organization of behavior is not increased (68). Likewise, the doubly transgenic model SPPswe/PS1dE9 mouse (up to 7 months of age) does not display marked abnormalities in its circadian organization of behavior, although there is an increase in daytime core body temperature compared with wildtypes (69). The APPxPS1 mouse displays a phase delay of its daytime wakefulness bout, although most parameters of the activity rhythms were not altered (70). Furthermore, old APPXPS1 animals displayed blunted diurnal variation in the SCN expression of Per2.

Overall, although studies of individual animal models of $A D$ yield varying results, possibly due to the different natures of these models, some interesting points emerge. One is that there is not necessarily a link between alterations in activity levels and the temporal organization of that behavior. This might be explained if the SCN and by extension SCN output is spared, but neuropathology impacts on cortical and subcortical areas implicated in motor control. There are undoubtedly further opportunities to gain more insight from such animal models, for example by using luciferase-based reporter systems for clock gene expression monitoring in real time in transgenic mouse models of $A D$ as well as the application of electrophysiological examination of SCN neuronal function in $A D$ models.

\section{Chronotherapeutics in AD}

Given that there is considerable evidence of circadian dysfunction in $A D$, therapeutic approaches that seek to target circadian abnormalities might provide novel avenues of treatment for AD. Such chronotherapeutic interventions might involve environmental (e.g., light therapy), behavioral (e.g., exercise), and/or pharmacological (e.g., melatonin) approaches (71). Satlin et al. (14) reported that evening light therapy led to stabilization of rhythms and improved sleep, although morning light therapy also significantly improved sleep (72). Morning light therapy also bolsters circadian rhythms and improves mini mental state examination scores, especially in the early stages of AD (73). Morning light therapy also seems to delay the onset of sundowning by an hour and a half, although the ratings of the agitation are not altered (74). Even in severe dementia morning light therapy might lead to phase advances of circadian rhythms and improve behavioral symptoms (75), and both morning and evening light therapy improves circadian parameters and leads to consolidation of sleep (74). Dowling et al. (76) did not report beneficial effects of light therapy on sleep parameters in institutionalized AD patients, but the light therapy did lead to a more stable circadian phase, and it has been suggested that those $A D$ patients with the most severe circadian abnormality are most likely to respond to light therapy (77). Efficacy of light therapy might also be enhanced significantly in combination with melatonin treatment (78). The use of light to simulate dawn and dusk, a more naturalistic light therapy approach, was found not to improve circadian amplitude or stability or cognitive parameters but did advance sleep onset, shorten sleep latency, and consolidate nocturnal sleep episodes (79).

Care settings for dementia patients are often dimly illuminated, a factor that might be of consequence when considering the potential beneficial impact of light on strengthening disrupted rhythms. Van Someren et al. (80) first reported on the potential therapeutic benefit of increasing incident illumination in care settings. Increasing light exposure of dementia patients does not impact on depression ratings, although there are suggestions that individual cases might benefit (81). Riemersma-van der Lek et al. (82) conducted a large randomized control trial increasing illumination levels in care facilities for elderly persons and found 
that long-term (approximately 1.5 years) increase in illumination levels slowed the decline in mini mental state examination scores (on average by .9) and lessened depression ratings and functional impairments. Such an approach is being trialled in AD patients, and the results of this study will be very illuminating with regard to the efficacy of a simple environmental intervention in improving cognitive, psychological, and behavioral symptoms of AD (83). $A$ recent study has indicated that lower levels of light exposure in AD patients during the winter might be associated with greater circadian rhythm abnormalities (84), highlighting the putative link between light exposure, seasonal effects, and circadian rhythm disturbances.

The therapeutic use of melatonin has also been examined in $A D$. Melatonin treatment in the evening is usually used to achieve a phase advance of the circadian rhythm, although morning melatonin might be used to produce a phase delay (85). A double-blind study of melatonin in AD revealed improvements in cognition as well as decreasing nocturnal activity and increased nocturnal sleep (86). A larger, multicenter study trial did not report any beneficial effects of melatonin on actigraphically determined sleep patterns in $A D$, although it is worthwhile to note that the timing of melatonin treatment in this trial ( 1 hour before bedtime, and so after the onset of endogenous melatonin synthesis) was specifically selected so as not to elicit phase shifts (87). Another trial examining the effects of melatonin on agitation, sleep, or circadian rhythms in AD failed to find any benefit of melatonin (88). There are many issues left to resolve with respect to the usefulness of melatonin in AD. If it is not effective in improving circadian rhythms and sleep on its own, then does it augment the effects of light therapy (78)? What dose of melatonin is used? And at what time is melatonin treatment administered? Is a long- or short-release formulation used? How well are different melatonin formulations tolerated in AD? Does the antidepressant agomelatine, which is an agonist for the MT1/ 2 melatonin receptors, have any efficacy in improving rhythms, sleep, or cognitive, behavioral, and/or psychological symptoms in $A D$ ? Another general point about light therapy versus pharmacological studies is the difficulty in achieving blinding in studies of light therapy, as opposed to trials with drug treatments. This factor might be important when considering the relative efficacies of light-based treatments versus drug-based treatments. Supplement 1 provides an overview of the roles of activitybased therapies in circadian rhythms in AD (89).

\section{Conclusions and Perspectives}

It is apparent that considerable circadian dysfunction occurs in $A D$, that such dysfunction seems to preface the clinical onset, and that disease severity seems to correlate with the magnitude of circadian dysfunction. With regard to chronotherapeutics, there are encouraging signs from studies of simple environmental interventions such as increasing the ambient illumination in care facilities, and light therapy also has shown some promise to date. It is important to note that the most marked circadian abnormalities noted in $A D$ are dampened amplitude and rhythm fragmentation rather than circadian misalignment (a more prevalent feature of mood disorders [90]). As such, interventions focusing on strengthening zeitgebers rather than phase-resetting might prove most fruitful. There is a need for large, randomized controlled clinical trials of chronotherapeutics in AD.

With regard to the nature of the circadian disruption that occurs in $A D$, there is much still to be understood. One aspect that might be of importance is the role of neuroinflammation in $\mathrm{AD}$ on SCN and circadian function. Alzheimer's disease, like many other neurodegenerative diseases, is associated with neuroinflammation (91) which can impact on SCN and circadian function $(9,92,93)$. Another area worthy of further investigation is the role that cholinergic cell loss has in circadian rhythm disturbance in $A D$ and whether anti-cholinesterase drugs might impact on such rhythms in AD.

In conclusion, understanding the nature of circadian rhythm disturbance in $A D$ and how such disturbances might be ameliorated for the improvement of patients and caregivers is a topic worthy of considerable future effort.

Research by ANC et al. is funded by Science Foundation Ireland, the Irish Health Research Board. ANC has no other financial disclosures or conflicts of interest. BTB is a member of advisory boards and/or gave presentations for the following companies: AstraZeneca, Lundbeck, Pfizer, Servier, and Wyeth; he receives funding from the National Health and Medical Research Council Australia. FH is on the advisory boards of Eli Lilly GmbH Germany, Janssen-Cilag, and Shire; he has received research support from Novartis Pharmaceuticals and Bayer Vital as well as travel grants from Novartis Pharmaceuticals and Bayer Vital; he has received travel grants from Novartis Pharmaceuticals, AstraZeneca Pharmaceutical, and Bayer Vital; he has received consulting fees from Janssen-Cilag, Novartis Pharmaceuticals, and Bayer Vital. JT has obtained financial support (lecture honoraria, grants for research projects and scientific meetings, advisory-board membership) from AstraZeneca, Bristol-Meyers Squibb, Ever Neuro Pharma, JanssenCilag, Lilly, Lundbeck, Medice Arzneimittel Pütter, Merz Pharmaceuticals, Novartis Pharma, Pfizer Pharma, Roche, Servier, and Shire, some of which are manufacturers of Alzheimer's-disease medication. $B S, S H, K F$, and $P K$ reported no biomedical financial interests or potential conflicts of interest.

Supplementary material cited in this article is available online.

1. Wulff K, Gatti S, Wettstein JG, Foster RG (2000): Sleep and circadian rhythm disruption in psychiatric and neurodegenerative disease. Nat Rev Neurosci 11:589-599.

2. Bianchetti A, Scuratti A, Zanetti O, Binetti G, Frisoni GB, Magni E, et al. (1995): Predictors of mortality and institutionalization in Alzheimer disease patients 1 year after discharge from an Alzheimer dementia unit. Dementia 6:108-112.

3. Reppert SM, Weaver DR (2002): Coordination of circadian timing in mammals. Nature 418:935-941.

4. Karatsoreos IN, Silver R (2007): Minireview: The neuroendocrinology of the suprachiasmatic nucleus as a conductor of body time in mammals. Endocrinology 148:5640-5647.

5. Dibner C, Schibler U, Albrecht U (2010): The mammalian circadian timing system: Organization and coordination of central and peripheral clocks. Annu Rev Physiol 72:517-549.

6. Schmidt C, Collette F, Cajochen C, Peigneux P (2007): A time to think: Circadian rhythms in human cognition. Cogn Neuropsychol 27: 755-789.

7. Waterhouse J (2010): Circadian rhythms and cognition. Prog Brain Res 185:131-153.

8. Gerstner JR, Yin JC (2010): Circadian rhythms and memory formation. Nat Rev Neurosci 11:577-588.

9. Coogan AN, Wyse CA (2008): Neuroimmunology of the circadian clock. Brain Res 1232:104-112.

10. Wyse CA, Coogan AN (2010): Impact of aging on diurnal expression patterns of CLOCK and BMAL1 in the mouse brain. Brain Res 1337: 21-31.

11. Kondratova AA, Kondratov RV (2012): The circadian clock and pathology of the ageing brain. Nat Rev Neurosci 13:325-335. 
12. Hofman MA, Swaab DF (2006): Living by the clock: The circadian pacemaker in older people. Ageing Res Rev 5:33-51.

13. McClung CA (2011): Circadian rhythms and mood regulation: Insights from pre-clinical models. Eur Neuropsychopharmacol 21(suppl 4): S683-S693.

14. Satlin A, Volicer L, Ross V, Herz L, Campbell S (1992): Bright light treatment of behavioral and sleep disturbances in patients with Alzheimer's disease. Am J Psychiatry 149:1028-1032.

15. Witting W, Kwa IH, Eikelenboom P, Mirmiran M, Swaab DF (1990): Alterations in the circadian rest-activity rhythm in aging and Alzheimer's disease. Biol Psychiatry 27:563-572.

16. Hatfield CF, Herbert J, van Someren EJ, Hodges JR, Hastings MH (2004): Disrupted daily activity/rest cycles in relation to daily cortisol rhythms of home-dwelling patients with early Alzheimer's dementia. Brain 127:1061-1074.

17. van Someren EJ, Hagebeuk EE, Lijzenga C, Scheltens $P$, de Rooij SE, Jonker C, et al. (1996): Circadian rest-activity rhythm disturbances in Alzheimer's disease. Biol Psychiatry 40:259-270.

18. Harper DG, Stopa EG, McKee AC, Satlin A, Harlan PC, Goldstein R, et al. (2001): Differential circadian rhythm disturbances in men with Alzheimer disease and frontotemporal degeneration. Arch Gen Psychiatry 58:353-360.

19. Young KW, Binns MA, Greenwood CE (2001): Meal delivery practices do not meet needs of Alzheimer patients with increased cognitive and behavioral difficulties in a long-term care facility. J Gerontol A Biol Sci Med Sci 56:M656-M661.

20. Carvalho-Bos SS, Riemersma-van der Lek RF, Waterhouse J, Reilly T, Van Someren EJ (2007): Strong association of the rest-activity rhythm with well-being in demented elderly women. Am J Geriatr Psychiatry 15:92-100.

21. Tranah GJ, Blackwell T, Stone KL, Ancoli-Israel S, Paudel ML, Ensrud KE, et al. (2011): Circadian activity rhythms and risk of incident dementia and mild cognitive impairment in older women. Ann Neurol 70: 722-732.

22. Wirz-Justice A, Werth E, Savaskan E, Knoblauch V, Gasio PF, MüllerSpahn F (2000): Haloperidol disrupts, clozapine reinstates the circadian rest-activity cycle in a patient with early-onset Alzheimer disease. Alzheimer Dis Assoc Disord 14:212-215.

23. Coogan AN, Papachatzaki MM, Clemens C, Baird A, Donev RM, Joosten J, et al. (2011): Haloperidol alters circadian clock gene product expression in the mouse brain. World J Biol Psychiatry 12:638-644.

24. Most El, Scheltens P, Van Someren EJ (2012): Increased skin temperature in Alzheimer's disease is associated with sleepiness. I Neural Transm 119:1185-1194.

25. Scarmeas N, Brandt J, Blacker D, Albert M, Hadjigeorgiou G, Dubois B, et al. (2007): Disruptive behavior as a predictor in Alzheimer disease. Arch Neurol 64:1755-1761.

26. Klaffke S, Staedt J (2006): Sundowning and circadian rhythm disorders in dementia. Acta Neurol Belg 106:168-175.

27. Martin J, Marler M, Shochat T, Ancoli-Israel S (2000): Circadian rhythms of agitation in institutionalized patients with Alzheimer's disease. Chronobiol Int 17:405-418.

28. Evans JG (1987): The onset of dementia. Ann Acad Med Singapore 16: 271-276.

29. Gallagher-Thompson D, Brooks JO 3rd, Bliwise D, Leader J, Yesavage JA (1992): The relations among caregiver stress, "sundowning" symptoms, and cognitive decline in Alzheimer's disease. J Am Geriatr Soc 40:807-810.

30. Volicer L, Harper DG, Manning BC, Goldstein R, Satlin A (2001): Sundowning and circadian rhythms in Alzheimer's disease. Am J Psychiatry 158:704-711.

31. Etcher L, Whall A, Kumar R, Devanand D, Yeragani V (2012): Nonlinear indices of circadian changes in individuals with dementia and aggression. Psychiatry Res 199:77-78.

32. Hu K, Van Someren EJ, Shea SA, Scheer FA (2009): Reduction of scale invariance of activity fluctuations with aging and Alzheimer's disease: Involvement of the circadian pacemaker. Proc Natl Acad Sci U S A 106: 2490-2494.

33. Hu K, Scheer FA, Ivanov P, Buijs RM, Shea SA (2007): The suprachiasmatic nucleus functions beyond circadian rhythm generation. Neuroscience 149:508-517.

34. Hayden KM, Zandi PP, Lyketsos CG, Tschanz JT, Norton MC, Khachaturian AS, et al. (2005): Apolipoprotein E genotype and mortality:
Findings from the Cache County Study. J Am Geriatr Soc 53: 935-942.

35. Stopa EG, Volicer L, Kuo-Leblanc V, Harper D, Lathi D, Tate B, et al. (1999): Pathologic evaluation of the human suprachiasmatic nucleus in severe dementia. J Neuropathol Exp Neurol 58:29-39.

36. Swaab DF, Fliers E, Partiman TS (1985): The suprachiasmatic nucleus of the human brain in relation to sex, age and senile dementia. Brain Res 342:37-44.

37. Zhou JN, Hofman MA, Swaab DF (1995): VIP neurons in the human SCN in relation to sex, age, and Alzheimer's disease. Neurobiol Aging 16:571-576.

38. Hofman MA, Zhou JN, Swaab DF (1996): Suprachiasmatic nucleus of the human brain: An immunocytochemical and morphometric analysis. Anat $\operatorname{Rec} 244: 552-562$.

39. Liu RY, Zhou JN, Hoogendijk WJ, van Heerikhuize J, Kamphorst W, Unmehopa UA, et al. (2000): Decreased vasopressin gene expression in the biological clock of Alzheimer disease patients with and without depression. J Neuropathol Exp Neurol 59:314-322.

40. Wu YH, Zhou JN, Van Heerikhuize J, Jockers R, Swaab DF (2007): Decreased MT1 melatonin receptor expression in the suprachiasmatic nucleus in aging and Alzheimer's disease. Neurobiol Aging 28: 1239-1247.

41. Coogan AN, Rawlings N, Luckman SM, Piggins HD (2001): Effects of neurotensin on discharge rates of rat suprachiasmatic nucleus neurons in vitro. Neuroscience 103:663-672.

42. Hughes AT, Fahey B, Cutler DJ, Coogan AN, Piggins HD (2004): Aberrant gating of photic input to the suprachiasmatic circadian pacemaker of mice lacking the VPAC2 receptor. I Neurosci 24: 3522-3526.

43. Liu RY, Zhou JN, Hoogendijk WJ, van Heerikhuize J, Kamphorst W, Unmehopa UA, et al. (2000): Decreased vasopressin gene expression in the biological clock of Alzheimer disease patients with and without depression. J Neuropathol Exp Neurol 59:314-322.

44. Harper DG, Stopa EG, McKee AC, Satlin A, Fish D, Volicer L (2004): Dementia severity and Lewy bodies affect circadian rhythms in Alzheimer disease. Neurobiol Aging 25:771-781.

45. Harper DG, Stopa EG, Kuo-Leblanc V, McKee AC, Asayama K, Volicer L, et al. (2008): Dorsomedial SCN neuronal subpopulations subserve different functions in human dementia. Brain 131:1609-1617.

46. Bina KG, Rusak B, Semba K (1993): Localization of cholinergic neurons in the forebrain and brainstem that project to the suprachiasmatic nucleus of the hypothalamus in rat. J Comp Neurol 335:295-307.

47. Hut RA, Van der Zee EA (2011): The cholinergic system, circadian rhythmicity, and time memory. Behav Brain Res 221:466-480.

48. Colwell CS, Kaufman CM, Menaker M (1993): Phase-shifting mechanisms in the mammalian circadian system: New light on the carbachol paradox. J Neurosci 13:1454-1459.

49. Erhardt C, Galani R, Jeltsch H, Cassel JC, Klosen P, Menet JS, et al. (2004): Modulation of photic resetting in rats by lesions of projections to the suprachiasmatic nuclei expressing p75 neurotrophin receptor. Eur J Neurosci 19:1773-1788.

50. Craig LA, Hong NS, Kopp J, McDonald RJ (2009): Cholinergic depletion of the medial septum followed by phase shifting does not impair memory or rest-activity rhythms measured under standard light/dark conditions in rats. Brain Res Bull 79:53-62.

51. Wisor JP, Edgar DM, Yesavage J, Ryan HS, McCormick CM, Lapustea N, et al. (2005): Sleep and circadian abnormalities in a transgenic mouse model of Alzheimer's disease: A role for cholinergic transmission. Neuroscience 131:375-385.

52. Cermakian N, Lamont EW, Boudreau P, Boivin DB (2011): Circadian clock gene expression in brain regions of Alzheimer's disease patients and control subjects. J Biol Rhythms 26:160-170.

53. Amir S, Lamont EW, Robinson B, Stewart J (2004): A circadian rhythm in the expression of PERIOD2 protein reveals a novel SCN-controlled oscillator in the oval nucleus of the bed nucleus of the stria terminalis. J Neurosci 24:781-790.

54. Tseng IJ, Liu HC, Yuan RY, Sheu JJ, Yu JM, Hu CJ (2010): Expression of inducible nitric oxide synthase (iNOS) and period 1 (PER1) clock gene products in different sleep stages of patients with cognitive impairment. J Clin Neurosci 17:1140-1143.

55. Cuninkova L, Brown SA (2008): Peripheral circadian oscillators: Interesting mechanisms and powerful tools. Ann N Y Acad Sci 1129: 358-370. 
56. Baird AL, Coogan AN, Siddiqui A, Donev RM, Thome J (2012): Adult attention-deficit hyperactivity disorder is associated with alterations in circadian rhythms at the behavioural, endocrine and molecular levels. Mol Psychiatry 17:988-995.

57. Trancikova A, Ramonet D, Moore DJ (2011): Genetic mouse models of neurodegenerative diseases. Prog Mol Biol Transl Sci 100:419-482.

58. Tate B, Aboody-Guterman KS, Morris AM, Walcott EC, Majocha RE, Marotta CA (1992): Disruption of circadian regulation by brain grafts that overexpress Alzheimer beta/A4 amyloid. Proc Natl Acad Sci U S A 89:7090-7094.

59. Furio AM, Cutrera RA, Castillo Thea V, Perez Lloret S, Riccio P, Caccuri $\mathrm{RL}$, et al. (2002): Effect of melatonin on changes in locomotor activity rhythm of Syrian hamsters injected with beta amyloid peptide 25-35 in the suprachiasmatic nuclei. Cell Mol Neurobiol 22:699-709.

60. Van Dam D, D'Hooge R, Staufenbiel M, Van Ginneken C, Van Meir F, De Deyn PP (2003): Age-dependent cognitive decline in the APP23 model precedes amyloid deposition. Eur J Neurosci 17:388-396.

61. Vloeberghs E, Van Dam D, Engelborghs S, Nagels G, Staufenbiel M, De Deyn PP (2004): Altered circadian locomotor activity in APP23 mice: A model for BPSD disturbances. Eur J Neurosci 20:2757-2766.

62. Bedrosian TA, Herring KL, Weil ZM, Nelson RJ (2011): Altered temporal patterns of anxiety in aged and amyloid precursor protein (APP) transgenic mice. Proc Natl Acad Sci U S A 108:11686-11691.

63. Gorman MR, Yellon S (2010): Lifespan daily locomotor activity rhythms in a mouse model of amyloid-induced neuropathology. Chronobiol Int 27:1159-1177.

64. Ambree O, Touma C, Gortz N, Keyvani K, Paulus W, Palme R, et al. (2006): Activity changes and marked stereotypic behavior precede Abeta pathology in TgCRND8 Alzheimer mice. Neurobiol Aging 27: 955-964.

65. Ring S, Weyer SW, Kilian SB, Waldron E, Pietrzik CU, Filippov MA, et al. (2007): The secreted beta-amyloid precursor protein ectodomain APPs alpha is sufficient to rescue the anatomical, behavioral, and electrophysiological abnormalities of APP-deficient mice. J Neurosci 27:7817-7826.

66. Sterniczuk R, Dyck RH, Laferla FM, Antle MC (2010): Characterization of the 3xTg-AD mouse model of Alzheimer's disease: Part 1. Circadian changes. Brain Res 1348:139-148.

67. Knight EM, Brown TM, Gümüsgöz S, Smith JC, Waters EJ, Allan SM, Lawrence CB (2012): Age-related changes in core body temperature and activity in triple-transgenic Alzheimer's disease (3xTgAD) mice [published online ahead of print October 25]. Dis Model Mech.

68. Jyoti A, Plano A, Riedel G, Platt B (2010): EEG, activity, and sleep architecture in a transgenic AbetaPPswe/PSEN1A246E Alzheimer's disease mouse. J Alzheimers Dis 22:873-887.

69. Baño Otalora B, Popovic N, Gambini J, Popovic M, Viña J, Bonet-Costa V, et al. (2012): Circadian system functionality, hippocampal oxidative stress, and spatial memory in the APPswe/PS1dE9 transgenic model of Alzheimer disease: Effects of melatonin or ramelteon. Chronobiol Int 29:822-834.

70. Duncan MJ, Smith JT, Franklin KM, Beckett TL, Murphy MP, St Clair DK, et al. (2012): Effects of aging and genotype on circadian rhythms, sleep, and clock gene expression in APPxPS1 knock-in mice, a model for Alzheimer's disease. Exp Neurol 236:249-258.

71. Coogan AN, Thome J (2011): Chronotherapeutics and psychiatry: Setting the clock to relieve the symptoms. World J Biol Psychiatry 12(suppl 1):40-43.

72. Mishima K, Okawa M, Hishikawa Y, Hozumi S, Hori H, Takahashi K (1994): Morning bright light therapy for sleep and behavior disorders in elderly patients with dementia. Acta Psychiatr Scand 89:1-7.

73. Yamadera H, Ito T, Suzuki H, Asayama K, Ito R, Endo S (2000): Effects of bright light on cognitive and sleep-wake (circadian) rhythm disturbances in Alzheimer-type dementia. Psychiatry Clin Neurosci 54: 352-353.

74. Ancoli-Israel S, Gehrman P, Martin JL, Shochat T, Marler M, CoreyBloom J, et al. (2003): Increased light exposure consolidates sleep and strengthens circadian rhythms in severe Alzheimer's disease patients. Behav Sleep Med 1:22-36.
75. Skjerve A, Holsten F, Aarsland D, Bjorvatn B, Nygaard HA, Johansen IM (2004): Improvement in behavioral symptoms and advance of activity acrophase after short-term bright light treatment in severe dementia. Psychiatry Clin Neurosci 58:343-347.

76. Dowling GA, Hubbard EM, Mastick J, Luxenberg JS, Burr RL, Van Someren EJ (2005): Effect of morning bright light treatment for restactivity disruption in institutionalized patients with severe Alzheimer's disease. Int Psychogeriatr 17:221-236.

77. Dowling GA, Mastick J, Hubbard EM, Luxenberg JS, Burr RL (2005): Effect of timed bright light treatment for rest-activity disruption in institutionalized patients with Alzheimer's disease. Int J Geriatr Psychiatry 20:738-743.

78. Dowling GA, Burr RL, Van Someren EJ, Hubbard EM, Luxenberg JS, Mastick J, et al. (2008): Melatonin and bright-light treatment for restactivity disruption in institutionalized patients with Alzheimer's disease. J Am Geriatr Soc 56:239-246.

79. Fontana Gasio P, Krauchi K, Cajochen C, Someren E, Amrhein I, Pache $M$, et al. (2003): Dawn-dusk simulation light therapy of disturbed circadian rest-activity cycles in demented elderly. Exp Gerontol 38: 207-216.

80. Van Someren EJ, Kessler A, Mirmiran M, Swaab DF (1997): Indirect bright light improves circadian rest-activity rhythm disturbances in demented patients. Biol Psychiatry 41:955-963.

81. Hickman SE, Barrick AL, Williams CS, Zimmerman S, Connell BR, Preisser JS, et al. (2007): The effect of ambient bright light therapy on depressive symptoms in persons with dementia. J Am Geriatr Soc 55: 1817-1824.

82. Riemersma-van der Lek RF, Swaab DF, Twisk J, Hol EM, Hoogendijk WJ, Van Someren EJ (2008): Effect of bright light and melatonin on cognitive and noncognitive function in elderly residents of group care facilities: A randomized controlled trial. JAMA 299: 2642-2655.

83. Most El, Scheltens P, Van Someren EJ (2010): Prevention of depression and sleep disturbances in elderly with memory-problems by activation of the biological clock with light-a randomized clinical trial. Trials 11:19.

84. Figueiro MG, Hamner R, Higgins P, Hornick T, Rea MS (2012): Field measurements of light exposures and circadian disruption in two populations of older adults. J Alzheimers Dis 31:711-715.

85. Lewy AJ (2007): Melatonin and human chronobiology. Cold Spring Harb Symp Quant Biol 72:623-636.

86. Asayama K, Yamadera H, Ito T, Suzuki H, Kudo Y, Endo S (2003): Double blind study of melatonin effects on the sleep-wake rhythm, cognitive and non-cognitive functions in Alzheimer type dementia. $J$ Nihon Med Sch 70:334-341.

87. Singer C, Tractenberg RE, Kaye J, Schafer K, Gamst A, Grundman M, et al. (2003): A multicenter, placebo-controlled trial of melatonin for sleep disturbance in Alzheimer's disease. Sleep 26:893-901.

88. Gehrman PR, Connor DJ, Martin JL, Shochat T, Corey-Bloom J, AncoliIsrael S (2009): Melatonin fails to improve sleep or agitation in double-blind randomized placebo-controlled trial of institutionalized patients with Alzheimer disease. Am J Geriatr Psychiatry 17: 166-169.

89. Baehr EK, Eastman Cl, Revelle W, Olson SH, Wolfe LF, Zee PC (2003): Circadian phase-shifting effects of nocturnal exercise in older compared with young adults. Am J Physiol Regul Integr Comp Physiol 284: R1542-1550.

90. Wirz-Justice A (2006): Biological rhythm disturbances in mood disorders. Int Clin Psychopharmacol 21(suppl 1):S11-S15.

91. Lee YJ, Han SB, Nam SY, Oh KW, Hong JT (2010): Inflammation and Alzheimer's disease. Arch Pharm Res 33:1539-1556.

92. Beynon AL, Coogan AN (2010): Diurnal, age, and immune regulation of interleukin-1 $\beta$ and interleukin-1 type 1 receptor in the mouse suprachiasmatic nucleus. Chronobiol Int 27:1546-1563.

93. Eyre H, Baune BT (2012): Neuroimmunomodulation in unipolar depression: A focus on chronobiology and chronotherapeutics. J Neural Transm 119:1147-1166. 